\title{
PENGARUH MODEL TIPE INSIDE OUTSIDE CIRCLE (IOC) TERHADAP HASIL BELAJAR MATEMATIKA DITINJAU DARI MOTIVASI BELAJAR
}

\author{
Ferryansyah $^{1}$, Indra Gormaks Pauba ${ }^{2}$ \\ ${ }^{1}$ Jurusan Pendidikan Matematika, Universitas Borneo Tarakan \\ ${ }^{2}$ Jurusan Pendidikan Matematika, Universitas Borneo Tarakan \\ 1vrsyah.math@gmail.com \\ 2indragormaks@gmail.com
}

\begin{abstract}
The purpose of this research is to clarify first to see the influence of the model (IOC and Conventional) on mathematics learning outcomes. Second, look at the influence of motivation (high and low) on students' mathematics learning outcomes. Third, look at the effect of interaction with the model (IOC and Conventional) and student motivation on students' mathematics learning outcomes. The activity was carried out at SMPN 5 Tarakan in the even semester of 2019-2020. The study used a quasi-experiment with $2 \times 2$ factorial. The population is class IX students of SMPN 5 Tarakan. Samples were taken by simple random sampling. Class IX1 is the experimental class and class IX-7 is the control class. Data were collected using a description test and questionnaire questions for motivation to learn mathematics. Descriptive methods include the mean and standard deviation. Inference method by analyzing the variance of two factors. The analysis at the 5\% significance level shows that the model (IOC and Conventional) has a p-value of 0.036, which means that it affects students' mathematics learning outcomes. Motivation to learn mathematics has an effect on student learning outcomes at a p-value of 0.000 . And there was no effect of mutual interaction between the model and motivation on the mathematics learning outcomes of students in class IX of SMPN 5 Tarakan with a p-value of 0.222 .
\end{abstract}

Keywords: Inside Outside Circle (IOC), Student's Learning Achievement, Student's Learning Motivation.

\begin{abstract}
Abstrak
Tujuan penelitian adalah memperjelas pertama melihat adanya pengaruh model (IOC dan Konvensional) terhadap hasil belajar matematika. Kedua, melihat adanya pengaruh motivasi (tinggi dan rendah) pada hasil belajar matematika siswa. Ketiga, melihat adanya pengaruh interaksi bersama model (IOC dan Konvensional) dan motivasi siswa pada hasil belajar matematika siswa. Kegiatan dilaksanakan di SMPN 5 Tarakan pada semester genap 2019-2020. Penelitian menggunakan eksperimen semu dengan faktorial 2x2. Populasi adalah siswa kelas IX SMPN 5 Tarakan. Sampel diambil dengan cara simple random sampling. Kelas IX-1 adalah kelas eksperimen dan kelas IX-7 adalah kelas kontrol. Data dikumpulkan menggunakan tes uraian dan pertanyaan angket untuk motivasi belajar matematika. Metode deskriptif meliputi mean dan standar deviasi. Metode inferensi dengan menganalisis varians dua faktor. Analisis pada taraf signifikansi 5\% menunjukkan bahwa model (IOC dan Konvensional) memiliki p-value 0,036 yang artinya berpengaruh terhadap hasil belajar matematika siswa. Motivasi belajar matematika berpengaruh terhadap hasil belajar siswa pada p-value 0,000. Dan tidak ditemukan adanya pengaruh interaksi bersama antara model dan motivasi pada hasil belajar matematika siswa di kelas IX SMPN 5 Tarakan dengan $p$-value 0,222.
\end{abstract}

Kata kunci: Inside Outside Circle (IOC), Hasil Belajar Matematika Siswa, Motivasi Belajar Siswa

Cara Menulis Sitasi: Ferryansyah, Ferryansyah., Pauba, G. Indra (2021). Pengaruh Model Tipe Inside Outside Circle (Ioc) Terhadap Hasil Belajar Matematika Ditinjau Dari Motivasi Belajar. Mathematic Education and Aplication Journal, volume 3 no. 1, halaman 35-40

Belajar matematika adalah suatu proses yang sengaja dirancang untuk menghasilkan situasi di mana seseorang dapat melakukan aktivitas matematika (Apino: 2012). Tujuan sesorang belajar matematika adalah untuk memberikan bekal kepada siswa agar dapat berpikir logik, analitik, 
sistematik, kreatif, kritis dan bekerjasama. Namun, pengajaran matematika didominasi oleh guru, metode pengajarannya cenderung menguntungkan (imperatif), dan proses komunikasinya satu arah. Karena lingkungan belajar tidak membantu memaknai materi, siswa ragu-ragu dalam proses pembelajaran dan pada akhirnya mempengaruhi hasil belajarnya.

Keadaan yang dipaparkan diatas juga terjadi di Sekolah Menengah Pertama Negeri 5 Tarakan (SMPN 5 Tarakan). Wawancara kepada guru matematika kelas IX di SMPN 5 Tarakan, peneliti memperoleh data masih rendahnya hasil belajar siswa dalam Ujian Tengah Semester (UTS). Dari 243 siswa, hanya terdapat 14 siswa yang mencapai KKM yaitu 70. Artinya hanya terdapat 5,76 \% siswa yang memperoleh nilai KKM dan terdapat 94,24 \% siswa yang tidak KKM.

Penyebab nilai siswa yang rendah antara lain 1) Pada dasarnya SMPN 5 Tarakan merupakan SMP di Kota Tarakan yang memakai acuan kurikulum 2013, dimana kurikulum tersebut proses pembelajaran dengan pendekatan saintifik di dalamnya terdapat 5M yaitu mengamati, menanya, mencoba, mengasosiasi, serta mengkomunikasikan. Akan tetapi pendekatan saintifik belum begitu tampak terlihat dalam kegiatan pembelajaran di kelas, melainkan guru yang bersangkutan masih menerapkan pembelajaran konvensional dengan metode ceramah. Saat guru aktif menjelaskan materi, siswa hanya cenderung menerima semua penjelasan dari guru, pada akhirnya murid pasif Ketika belajar; 2) Siswa kurang dilibatkan dalam kegiatan belajar, hal itu terlihat dari kurangnya banyaknya siswa merespon pertanyaan yang guru lontarkan. Tidak ada siswa yang berani bertanya kepada guru ketika tidak mengerti apa yang sedang dijelaskan; 3) Siswa kurang memperhatikan pelajaran, hal itu terlihat ketika guru menjelaskan topik pelajaran yang diajarkan mereka asyik bercerita bersama temannya, dan ketika diberikan latihan soal untuk dikerjakan sebagian siswa menyontek dengan teman sebangkunya.

Selain rendah nya hasil belajar siswa, penyebab lain berdasarakan observasi adalah motivasi belajar siswa. Beberapa masalah dalam motivasi belajar siswa, yaitu : 1) ketika dalam kegiatan belajar mata pelajaran matematika siswa kurang antusias belajar di kelas, hal itu terlihat ada beberapa siswa yang lupa membawa alat tulis dan sibuk berbincang dengan teman ketika guru sedang menjelaskan pelajaran 2) ketika siswa diberikan soal jarang siswa mengerjakannya dan pada akhirnya soal yang diberikan dijadikan pekerjaan rumah; 3) siswa terlihat mudah putus asa dan menyerah ketika menemui kesulitan dalam mengerjakan soal 4) apabila diberikan latihan soal siswa menyontek dengan teman sebangkunya; 5) jarang siswa bertanya pada guru meskipun diberi kesempatan untuk bertanya, terlihat ketika guru bertanya kepada siswa, Akan tetapi tidak satu pun siswa pun yang berani mengungkapkan pendapatnya 6) ketika ada jam pelajaran kosong siswa tidak punya inisiatif untuk mempelajari sendiri pelajaran dan mencoba menyelesaikan latihan yang ada.

Salah satu solusi mengatasi masalah di atas adalah penggunakan model kooperatif InsideOutside Circle (IOC). Penerapan model IOC diperuntukkan agar siswa belajar berkelompok dengan berbagi informasi serta saling memberi motivasi dalam belajar di kelas (Lie, 2009 : 65). Siswa mendapatkan informasi tidak hanya dari guru saja namun siswa yang masih bingung dengan 
penjelasan dari guru juga bisa mendapatkan informasi dari temannya sebayanya. Dengan menggunakan model tipe $I O C$ ini, diharapkan siswa akan terfokus dan tertarik dalam belajar matematika karena semua siswa terlibat dalam pembelajaran, dari pada siswa hanya mendengarkan guru berceramah yang nantinya akan membuat mereka bosan dan malas dalam pembelajaran. Hal ini dipertegas oleh Huda (2013 : 145) bahwa model IOC merupakan penggabungan antara belajar kelompok dan belajar individu. Oleh karena itu, penelitian ini bertujuan untuk mengetahui adanya pertama, pengaruh model (IOC dan Konvensional) terhadap hasil belajar matematika. Kedua, pengaruh motivasi belajar baik kategori tinggi maupun rendah terhadap hasil belajar matematika. Ketiga, pengaruh interaksi Bersama antara model (IOC dan Konvensional) dengan motivasi belajar erhadap hasil belajar matematika pada siswa kelas IX SMPN 5 Tarakan.

\section{METODE}

Metode penelitian menggunakan kuantitatif karena jenis data yang dianalisis adalah dalam bentuk numerik. Jenis penelitian menggunakan semi empiris. Menurut Sugiyono (2015:11) Semiempiris adalah salah satu jenis penelitian dengan kelompok kontrol, tetapi tidak secara sempurna dapat mengontrol variabel eksternal yang mempengaruhi kelompok eksperimen. Penelitian menggunakan desain Posttest Only Control Group Desig. Dan juga factorial yang diolah pada tingkat faktor $2 \times 2$. Desain faktorial digunakan untuk menentukan pengaruh dua faktor atau lebih. Hal ini karena setiap pengamatan memberikan informasi tentang semua faktor. Lokasi penelitian di SMPN 5 Tarakan di Kota Tarakan, Provinsi Kalimantan Utara, Kecamatan Tarakan Timur. Penelitian dilakukan pada semester genap pada tahun akademik 2019/2020. Subjek penelitian ini adalah kelas IX SMPN 5 Tarakan dari kelas IX-1 sampai dengan IX-8, yang memliki siswa 243 orang. Sampel memakai teknik probabilistic sampling. Kelas IX-1 sebagai kelompok eksperimen yang diajar dengan model IOC dan kelas IX-7 sebagai kelompok kontrol yang diajar dengan model konvensional.

Teknik mengumpulkan data menggunakan tes dan angket. Jenis tes yang digunakan adalah tes tertulis berupa pertanyaan deskriptif atau soal uraian. Tes dilakukan di akhir (post-test). Sedangkan untuk mengukur kategori motivasi belajar siswa digunakan angket motivasi belajar. Menurut Sugiyono (2016 : 207) ada dua jenis perhitungan statistik yang dapat pergunakan menghitung dan menganalisis data diantaranya statistik deskriptif dan statistik inferensi. Penggunaan analisis statistik deskriptif untuk menghitung mean (mean) dan standar deviasi (standar deviasi), dan penggunaan analisis inferensi statistik yang meliputi pengujian hipotesis dan prasyarat meliputi normalitas dan homogenitas dan penyajian hipotesis. 


\section{HASIL DAN PEMBAHASAN}

Pengolahan data dengan SPSS 21.0 memperlihatkan bahwa nilai mean dan standar deviasi baik pada kelompok eksperimen dengan model IOC dan kelompok kontrol dengan model konvensional pada tabel di bawah ini :

Tabel 1. Analisis Deskriptif Hasil Belajar Matematika

\begin{tabular}{|l|c|c|c|}
\hline \multicolumn{1}{|c|}{ Kelas } & Siswa & Nilai Rata-Rata & Standar Deviasi \\
\hline $\begin{array}{l}\text { Eksperimen } \\
\text { Inside Outside Circle) }\end{array}$ & 32 & 73,73 & 12,70 \\
\hline $\begin{array}{l}\text { Kontrol } \\
\text { (Konvensional) }\end{array}$ & 32 & 65,40 & 12,09 \\
\hline
\end{tabular}

Pengelompokkan tes nilai belajar matematika siswa terlihat pada tabel berikut

Tabel 2. Kategori Hasil Belajar Matematika Siswa

\begin{tabular}{|c|c|c|c|c|}
\hline \multirow{2}{*}{ Nilai } & \multicolumn{2}{|c|}{ Inside Outside Circle } & \multicolumn{2}{c|}{ Konvensional } \\
\cline { 2 - 5 } & Frekuensi & $(\%)$ & Frekuensi & $(\%)$ \\
\hline $89-100$ & 3 & 9,37 & 0 & 0 \\
\hline $77-88$ & 10 & 31,25 & 15 & 15,62 \\
\hline $65-76$ & 13 & 40,62 & 10 & 31,25 \\
\hline $0-65$ & 6 & 18,75 & 17 & 53,12 \\
\hline
\end{tabular}

Hasil analisis deskriptif data hasil belajar matematika juga dikelompokkan menurut motivasi belajar seluruh kelas. Hasil ini dari penerapan model pembelajaran IOC dan model pembelajaran konvesional. Lihat tabel berikut ini.

Tabel 3. Analisis Deskriptif Motivasi Belajar Siswa

\begin{tabular}{|l|c|c|c|}
\hline \multicolumn{1}{|c|}{ Kelas } & Siswa & Nilai Rata-Rata & Standar Deviasi \\
\hline $\begin{array}{l}\text { Eksperimen } \\
\text { (Inside Outside Circle) }\end{array}$ & 32 & 2,04 & 0,27 \\
\hline $\begin{array}{l}\text { Kontrol } \\
\text { (Konvensional) }\end{array}$ & 32 & 1,72 & 0,28 \\
\hline
\end{tabular}

Pengelompokkan hasil angket motivasi belajar siswa terlihat pada tabel di bawah ini

Tabel 4. Kategori Motivasi Belajar Siswa

\begin{tabular}{|c|c|c|c|c|c|}
\hline \multirow{2}{*}{$\begin{array}{c}\text { Presentase Skor } \\
\text { Motivasi }\end{array}$} & \multirow{2}{*}{ Kategori } & \multicolumn{2}{|c|}{ Inside Outside Circle } & \multicolumn{2}{c|}{ Konvensional } \\
\cline { 3 - 6 } & & Frekuensi & $(\%)$ & Frekuensi & $(\%)$ \\
\hline $\mathrm{x} \geq 1,56$ & Tinggi & 25 & 78,12 & 9 & 28,12 \\
\hline $\mathrm{x}<1,56$ & Rendah & 7 & 21,87 & 23 & 71,87 \\
\hline
\end{tabular}

Hasil analisis berikut menggambarkan hasil belajar matematika siswa ditinjau dari motivasi belajarnya pada kelompok eksperimen dan kontrol pada tabel berikut. 
Pengaruh Model Tipe Inside Outside Circle (IOC) Terhadap Hasil Belajar Matematika Ditinjau dari Motivasi Belajar 39 Ferryansyah, Pauba.

Tabel 5. Hasil Analisis Deskriptif Hasil Belajar Matematika Ditinjau dari Motivasi Belajar Siswa

\begin{tabular}{|c|c|c|c|}
\hline \multirow[b]{2}{*}{ Motivasi Belajar } & \multicolumn{2}{|c|}{ Model Pembelajaran } & \multirow{2}{*}{$\begin{array}{c}\text { Keseluruhan pada } \\
\text { Faktor Motivasi } \\
\text { Belajar }\end{array}$} \\
\hline & Inside Outside Circle & Konvensional & \\
\hline Tinggi & $\begin{array}{c}\mathrm{n}=25 \\
\mathrm{x}=77,32 \\
\mathrm{~s}=10,62\end{array}$ & $\begin{array}{c}\mathrm{n}=9 \\
\mathrm{x}=76,89 \\
\mathrm{~s}=8,06\end{array}$ & $\begin{array}{c}\mathrm{n}=34 \\
\mathrm{x}=78,01 \\
\mathrm{~s}=9,95\end{array}$ \\
\hline Rendah & $\begin{array}{c}n=7 \\
x=60,88 \\
s=11,67\end{array}$ & $\begin{array}{c}n=23 \\
x=59,76 \\
s=7,93\end{array}$ & $\begin{array}{c}\mathrm{n}=30 \\
\mathrm{x}=59,99 \\
\mathrm{~s}=8,72\end{array}$ \\
\hline
\end{tabular}

Saat menggunakan uji two-way ANOVA pada hipotesis diperoleh nilai p-value adalah 0,036. $\mathrm{H}_{0}$ ditolak karena nilai $p$-value $<0,05$. Hal ini berarti model yang digunakan berpengaruh terhadap hasil belajar matematika kelas IX di SMPN 5 Tarakan. Kegiatan pembelajaran dengan model Inside Outside Circle (IOC) memungkinkan kepada siswa untuk berbagi informasi tentang kelompok tertentu dan untuk berkumpul kembali serta berinteraksi tanpa berada dalam kelompoknya. Hal ini tentu membantu siswa untuk memberikan informasi yang mudah dipahami dalam belajar. Kondisi ini sejalan dengan Djamarah (2010: 08) yang mengatakan model IOC memungkinkan kepada siswa untuk saling berbagi pendapat ataupun informasi sekaligus kepada temannya.

Saat menggunakan uji two-way ANOVA diperoleh nilai $p$-value untuk motivasi belajar adalah 0,000. $\mathrm{H}_{02}$ ditolak karena $p$-value $<0,05$. Hal ini berarti motivasi belajar berpengaruh terhadap nilai hasil belajar matematika siswa. Motivasi belajar seorang siswa mempengaruhi hasil belajar matematika. Sudah dijelaskan di depan bahwa motivasi belajar matematika adalah faktor yang mempunyai pengaruh pada hasil belajar matematika. hasil ini sejalan dengan Pratutik (2013) faktor intern yang mempenagruhi hasil belajar salah satu nya adalah motivasi. Selain itu juga tingkah laku timbul dari ada nya motivasi, yang pada akhirnya akan mempengaruhi hasil belajar (Hamalik, 2013).

Hasil pengujian dengan two-way ANOVA didapatkan nilai $p$-value interaksi bersama antara model dengan motivasi belajar siswa sebesar 0,222. $\mathrm{H}_{0}$ diterima karena nilai $\mathrm{p}>0,05$. Artinya interaksi bersama antara model dan motivasi belajar sama sekali tidak berpengaruh terhadap hasil belajar matematika. Masing-masing variabel baik model maupun motovasi belajar memiliki pengaruhnya masing-masing terhadap hasil belajar, maka Ketika siswa belajar menggunakan model IOC dan konvensional, siswa yang memiliki motivasi level tinggi tertarik menemukan dan memecahkan masalah matematika dengan benar. Siswa juga akan perhatian dan berpartisipasi akatif dalam proses pembelajaran. Di sisi lain, siswa yang kurang termotivasi sering terasing dari temannya, menjalani kehidupan yang tertutup, tidak mampu menyelesaikan persoalan yang diberikan, tidak 
percaya diri, dan sering putus asa yang akan berdampak negatif pada hasil belajar siswa dalam belajar matematika. Motivasi belajar tentu sangat membantu dalam mengoptimalkan hasil belajar siswa.

\section{KESIMPULAN}

Adapun kesimpulan penelitian ini berdasarkan uraian di atas adalah

1. Model pembelajaran (IOC dan konvensional) berpengaruh terhadap hasil belajar matematika siswa di kelas IX SMPN 5 Tarakan.

2. Motivasi belajar siswa berpengaruh terhadap hasil belajar matematika siswa di kelas IX SMPN 5 Tarakan.

3. Tidak ada pengaruh interaksi bersama antara model pembelajaran (IOC dan konvensional) dengan motivasi belajar terhadap hasil belajar matematika siswa di kelas IX SMPN 5 Tarakan.

\section{DAFTAR PUSTAKA}

Apino. (2012). Hakikat Pembelajaran Matematika, (online), (http://repo.iaintulungagung.ac.id/339/4/BAB\%20II.pdf), diakses 16 Februari 2019.

Djamarah, S.B. (2010). Guru dan Anak Didik dalam Interkasi Edukatif Suatu Pendekatan Teoritis Psikologis. Jakarta : Rineka Cipta.

Hamalik, Oemar. (2013). Proses Belajar Mengajar. Jakarta : Bumi Aksara

Huda, Miftahul. (2013). Cooperative Learning. Yogyakarta: Pustaka Belajar.

Lie, A. (2009). Cooperative Learning. Jakarta: Grasindo.

Pratutik. (2013). Hubungan Motivasi Belajar Dengan Hasil Belajar PKn Pada Siswa Negeri 1 Kranggan Temanggung. Tersedia di : http://repository.uksw.edu/bitstream/. Diakses pada tanggal 30 Juli 2018.

Sugiyono. (2016). Metode Penelitian Kuantitatif Kualitataif dan Kombinasi (Mixed

Methods).

Bandung: Alfabeta.

Sugiyono. (2015). Metode Penelitian Pendidikan: Pendekatan Kuantitatif,Kualitatif, dan $R \& D$. Bandung: Alfabeta. 